\title{
Implicações do Programa Ensino Médio Inovador no Ensino de Ciências da Natureza na Rede Estadual de Educação de Curitiba/PR
}

\author{
Viviane Maria Rauth ${ }^{1}$ \\ Orliney Maciel Guimarães ${ }^{2}$
}

\begin{abstract}
Resumo:
0 Programa Ensino Médio Inovador (ProEMI) é uma política pública educacional com 0 objetivo de fomentar propostas curriculares inovadoras nas escolas de Ensino Médio. Com 0 intuito de compreender como estas propostas vêm sendo desenvolvidas propomo-nos discutir as implicações desse programa no âmbito do ensino de Ciências da Natureza nas escolas estaduais de Curitiba-Paraná, considerando o macrocampo Iniciação Científica e Pesquisa. A constituição de dados deu-se por meio de três técnicas: a análise documental, a entrevista e o questionário, tendo como sujeitos da pesquisa os gestores, professores de Biologia, Física e Química e os respectivos alunos que participaram das ações desenvolvidas no âmbito do programa. A abordagem da pesquisa fundamentou-se no Ciclo de Políticas de Stephen Ball e colaboradores e a análise dos dados foi realizada a partir da Análise Textual Discursiva. Foi possível constatar que os efeitos do ProEMI nas escolas investigadas foram de primeira ordem, caracterizados por mudanças apenas nas práticas fora da sala de aula e
\end{abstract}

1 Mestre em Educação em Ciências e Matemática pela UFPR e professora de Biologia da rede pública de ensino do Paraná. vivianerauth@gmail.com

2 Doutora em Ciências pela USP/São Carlos (1997), mestre em Ciências pela USP/FFCLRP de Ribeirão Preto (1991). Possui Licenciatura em Química pela Universidade Federal de Uberlândia (1988). Professora-titular da Universidade Federal do Paraná, na qual atua desde 1992. Credenciada como professora permanente no Programa de Pós-Graduação em Educação da UFPR, na Linha de Pesquisa: Cultura, Escola e Ensino e no Mestrado Profissional em Química em Rede Nacional (PROFQUI). Coordena o Núcleo de Educação em Química da UFPR desde 2000. Foi tutora do Grupo PET-Química de 2008-2014 e atualmente é coordenadora do curso de Bacharelado e Licenciatura em Química da UFPR. Atua na área de Ensino de Química com interesse nos seguintes temas: formação inicial e continuada de professores, currículo e avaliação, experimentação no ensino de Ciências e Ensino de Ciências para Deficientes Visuais. orliney@ufpr.br 
na estrutura parcial da escola. Pouca coisa mudou em relação ao currículo, a avaliação, os padrões de acesso ou oportunidades, constatando-se que estas mudanças foram restritas e privilegiaram poucos alunos.

Palavras-chave: Programa Ensino Médio Inovador. Ensino Médio. Ensino de Ciências da Natureza.

\title{
IMPLICATIONS OF THE INNOVATIVE HIGH SCHOOL PROGRAM IN THE TEACHING OF NATURAL SCIENCES IN THE STATE EDUCATION NETWORK OF CURITIBA/PR
}

\begin{abstract}
:
The Innovative High School Program (IHSP) is an educational public policy aimed at fostering innovative curricular proposals in high schools. In order to understand how these proposals are being developed, we propose to discuss the implications of this program in the field of Nature Science teaching in the state schools of Curitiba-Paraná, considering the macro-field Scientific Initiation and Research. Data were collected through three techniques: documentary analysis, interview and questionnaire. The research subjects were managers, Biology, Physics and Chemistry professors and the respective students who participated in the actions developed under the program. The approach of the analysis was based on the Policy Cycle of Stephen Ball and collaborators and from the Discursive Textual Analysis. It was possible to verify that the effects of IHSP in the schools investigated were of first order, characterized by changes only in the practices outside the classroom and in the partial structure of the school. Little has changed regarding curriculum, assessment, access patterns or opportunities, and these changes have been restricted and privileged few students.
\end{abstract}

Keywords: Innovative High School Program. High school. Teaching science of nature.

Recebido em: 10/7/2017

Aceito em: 5/11/2017 
O Ensino Médio (EM) tem apresentado muitas fragilidades em termos de acesso, permanência e qualidade da educação ofertada aos jovens estudantes, bem como passa por debates constantes em termos de definição de sua identidade, seu financiamento e sua organização curricular.

Dando destaque às políticas educacionais para a Educação Básica é possível perceber que pela primeira vez estamos observando um movimento em direção à construção de uma política educacional de Estado voltada especificamente à última etapa deste nível de ensino. Fazem parte deste movimento as orientações preconizadas pela LDB 9394/96, a qual coloca o EM como última etapa da Educação Básica, possibilitando uma melhora significativa no seu financiamento com a lei do Fundo de Desenvolvimento da Educação Básica (Fundeb) e contribuindo para o estabelecimento da identidade do EM; sua obrigatoriedade promulgada pela Emenda Constitucional no 59 até 2016 e universalização até 2020; o Pacto Nacional pelo Fortalecimento do Ensino Médio realizado em 2014 que prevê a formação continuada de professores; a atualização das Diretrizes Curriculares Nacionais para o Ensino Médio (DCNEM) e o Programa Ensino Médio Inovador (ProEMI).

O ProEMI, instituído pela Portaria nº 971, de 9/10/2009, tem por objetivo fomentar propostas curriculares inovadoras nas escolas de EM, cujas orientações possam proporcionar o debate em torno da conformação de um "currículo dinâmico, flexível e que atenda às demandas da sociedade contemporânea" (BRASIL, 2013b, p. 10).

Este Programa aponta para a necessidade de mudanças na organização curricular do EM, a qual passa por uma série de desafios, entre os quais a necessidade de ofertar um currículo menos fragmentado e hierarquizado. O ProEMI, portanto, intenta o redesenho curricular das escolas de Ensino Médio em direção à construção de propostas baseadas em uma perspectiva de integração curricular. Introduzido inicialmente em 18 Estados, entre os anos de 2009 e 2010, no Estado do Paraná a adesão ocorreu em 2010, considerando a proposta local de inovação curricular conhecida por "Ensino Médio Organizado por Blocos de Disciplinas Semestrais” (EMBDS). Esta nova organização curricular continua sendo por série, porém dividida em dois blocos de disciplinas, as quais são 
ofertadas por semestre com cem dias letivos. Cada bloco possui seis disciplinas organizadas numa matriz única para o Estado do Paraná, e o estudante conclui a série quando cumprir os dois blocos de disciplinas ofertados por semestre letivo. O ProEMI foi instituído como Programa de Atividades Complementares Curriculares em Contraturno na Educação Básica na Rede Estadual de Ensino no Paraná considerando o EMBDS.

Dessa maneira, propusemo-nos a investigar o ProEMI nas escolas estaduais de Curitiba-PR que optaram por aderir a esse programa por meio do macrocampo Iniciação Científica e Pesquisa (ICP). Para isso levantamos o seguinte problema de pesquisa: Quais as implicações do Programa Ensino Médio Inovador no ensino de Ciências da Natureza ${ }^{3}$ nas escolas estaduais de Curitiba-PR cujas propostas foram submetidas tendo em vista o macrocampo ICP? Partindo desta indagação temos por objetivo geral discutir as implicações do Programa Ensino Médio Inovador, tendo em vista analisá-las no âmbito do ensino de Ciências da Natureza nas escolas estaduais de Curitiba-Paraná, considerando o macrocampo Iniciação Científica e Pesquisa (ICP) proposto por este Programa.

No documento orientador do ProEMI referente ao ano de 2013, tanto na versão preliminar (BRASIL, 2013a) quanto na definitiva (BRASIL, 2013b), os macrocampos são definidos como campos de ação pedagógico-curricular considerados eixos pelos quais é possível desenvolver "atividades interativas, integradoras e integradas dos saberes, dos tempos, dos espaços e dos sujeitos envolvidos com a ação educacional", possibilitando assim a integração curricular (BRASIL, 2013b, p. 15).

Salientamos que o macrocampo ICP foi o ponto de partida para a constituição de dados desta investigação e também por considerarmos a sua relevância no processo de inovação educacional especificamente no ensino de Ciências da Natureza.

\footnotetext{
${ }^{3}$ Compreende-se por ensino de Ciências da Natureza a área de estudo que abrange as disciplinas de Biologia, Física e Química entendidas aqui como componentes constituintes da área de Ciências da Natureza conforme as Diretrizes Curriculares Nacionais de 2012 para o Ensino Médio no Brasil. Sempre que nos referirmos ao ensino de Ciências da Natureza, estamos tratando desses componentes curriculares.
} 
Conforme indicam os documentos orientadores do ProEMI (BRASIL, 2013a; 2013b), o macrocampo ICP deve contemplar ações que propiciam a integração entre teoria e prática podendo ser desenvolvidas em laboratórios e/ ou em outros espaços. As atividades devem ser dirigidas de modo a desenvolver os conhecimentos científicos, aproximando-os da maneira pela qual a Ciência é produzida e socializada.

Ao trabalhar com o macrocampo ICP as escolas deverão considerar ainda o "desenvolvimento de metodologias para sistematização do conhecimento, por meio da experimentação", além de permitir o entrelaçamento com o mundo do trabalho (BRASIL, 2013a, p. 17). Este macrocampo pode abranger aspectos teóricos e metodológicos da pesquisa nas áreas de Linguagem, Matemática, Ciências da Natureza e Humanas. O nosso interesse foi especificamente pela área de Ciências da Natureza.

Lembramos que esta investigação é um recorte de uma dissertação de Mestrado, por meio da qual foi possível estabelecer as seguintes categorias emergentes: Ensino Médio: Finalidades e Práticas; Compreensões e Significados sobre o ProEMI; Limites e Possibilidades do ProEMI; Concepções sobre Inovação e Abordagens Inovadoras no Ensino de Ciências. A partir dessas categorias propomo-nos discutir neste artigo as implicações do ProEMI no ensino de Ciências da Natureza nas escolas estaduais de Curitiba-PR cujas propostas foram submetidas tendo em vista o macrocampo ICP.

Dessa forma, esperamos com este estudo contribuir para as reflexões e debates sobre a melhoria da qualidade do ensino de Ciências, e de forma consubstanciada, sobre a melhoria do Ensino Médio brasileiro.

\section{Traçando Caminhos para Desvelar as Implicações do Proemi}

Houve a necessidade de realizarmos alguns recortes no sentido de propiciar uma análise da política educacional no contexto da Educação em Ciências. Em virtude de algumas limitações em termos de espaço e tempo, 
optamos como locus da investigação a rede pública estadual de ensino no município de Curitiba - Paraná, tendo como sujeitos da pesquisa os gestores, professores e alunos.

Para a escolha das escolas que foram investigadas realizamos, em março de 2013, um levantamento por meio de um aplicativo denominado Consulta Escolas, disponível no site da Secretaria Estadual de Educação no Paraná (Seed-PR). Naquela ocasião mapeamos 17 colégios em Curitiba que haviam sido contemplados com o ProEMI. Como fizemos um recorte dentro do macrocampo ICP constatamos que dos 17 colégios apenas 9 ofertavam este macrocampo. Os professores desses colégios, responsáveis pelos projetos de Ciências da Natureza, foram contatados e aceitaram participar da pesquisa, totalizando 12 professores entrevistados. Além dos docentes, também participaram da pesquisa todos os alunos que naquele momento estavam vinculados e atuando nos referidos projetos e o gestor responsável pelo ProEMI no Paraná.

Para a construção do quadro teórico, tendo em vista a análise dos dados, buscamos elementos no campo de análise das políticas públicas, em especial as discussões relacionadas aos percursos metodológicos das pesquisas neste campo. Assim, optou-se pela Abordagem do Ciclo de Políticas (ACP) de Stephen Ball e colaboradores como abordagem metodológica, proporcionando assim uma análise mais abrangente e consistente com o campo de pesquisa em políticas educacionais.

Segundo Mainardes (2006, p. 48), esta abordagem permitiria “a análise crítica da trajetória de programas e políticas educacionais desde sua formulação inicial até a sua implementação no contexto da prática e seus efeitos". É uma maneira de pesquisar e teorizar as políticas, uma metodologia para compreender a política no seu movimento. É nesse movimento que alguns aspectos podem ser evidenciados, uns mais, outros menos (MAINARDES, 2006).

Partindo desta metodologia é possível visualizar o ProEMI em seus diferentes contextos e como tais estão intrinsecamente relacionados, direcionam a forma como este Programa vem sendo discutido nas escolas públicas estaduais de Ensino Médio em Curitiba-PR. 
Desse modo, destacamos que para contemplar os contextos da ACP a constituição de dados se deu por meio de três técnicas: a análise documental, a entrevista semiestruturada e o questionário, tendo como sujeitos da pesquisa os gestores, professores de Biologia, Física e Química e todos os respectivos alunos que participaram das ações dentro do macrocampo Iniciação Científica e Pesquisa, proporcionadas pelo Programa em questão. Destacamos que os projetos de ICP analisados foram aqueles desenvolvidos nas 9 escolas participantes da pesquisa. Depois de constituídos os dados passaram a fazer parte do corpus da pesquisa como segue no Quadro 1:

Quadro 1 - Corpus da Pesquisa

\begin{tabular}{|l|l|}
\hline Corpus da Pesquisa & Sujeitos da Pesquisa \\
\hline 12 Entrevistas com professores & $\begin{array}{l}\text { 5 Professores de Biologia } \\
\text { (PB1, PB2, PB3, PB4 e PB5) } \\
\text { 4 Professores de Química } \\
\text { (PQ1, PQ2, PQ3 e PQ4) } \\
\text { 3 Professores de Física } \\
\text { (PF1, PF2 e PF3) }\end{array}$ \\
\hline 67 Questionários & $\begin{array}{l}\text { 67 Alunos } \\
\text { (A1, A2, A3, A4, .., (A67) }\end{array}$ \\
\hline 9 Projetos de Iniciação Científica e Pesquisa & $\begin{array}{l}\text { 9 Colégios Públicos Estaduais } \\
\text { (C1, C2, C3, C4, C5, C6, C7, C8 e C9) }\end{array}$ \\
\hline 1 Entrevista com a gestora do ProEMI no Paraná & $\begin{array}{l}\text { Gestores Esfera Estadual } \\
\text { (GE) }\end{array}$ \\
\hline $\begin{array}{l}\text { Documento Orientador ProEMI - 2013a } \\
\text { Documento Orientador ProEMI - 2013b }\end{array}$ & \begin{tabular}{l} 
Gestores Esfera Federal \\
\hline
\end{tabular}
\end{tabular}

Fonte: As autoras, 2015.

De posse dos dados constituídos a partir dos documentos orientadores do ProEMI, dos Projetos de Iniciação Científica e Pesquisa das escolas, das entrevistas transcritas e dos questionários, organizamos um conjunto de dados textuais aos quais precisamos atribuir sentidos. Para tratar estes dados usamos as contribuições da Análise Textual Discursiva (ATD) de Moraes e Galiazzi (2007). 


\section{Os Efeitos do Proemi no Âmbito do Ensino Médio}

Os efeitos do ProEMI podem ser considerados de primeira ordem, indicando que as mudanças nas escolas com a vinda deste Programa foram superficiais (CARBONELL, 2002), mas sinalizam possibilidades profícuas para o Ensino Médio, particularmente por aqueles que participam das ações no contraturno.

Stephen Ball explora a ideia sobre os efeitos de primeira ordem e de segunda ordem. Para este autor, efeitos de primeira ordem correspondem "a mudanças na prática ou na estrutura e são evidentes em lugares específicos ou no sistema como um todo, e os efeitos de segunda ordem referem-se ao impacto dessas mudanças nos padrões de acesso social, oportunidade e justiça social" (BALL, 1994 apud MAINARDES, 2006, p. 55).

Na visão dos professores de Ciências, "o principal elemento de sucesso, até o momento, foram os recursos financeiros que propiciaram a aquisição" de equipamentos para a escola (PF2). O professor PF2 destaca, ainda, que "antes do Programa Ensino Médio Inovador era praticamente impossível você conseguir verba para comprar equipamento". Desse modo, como afirma a gestão do Programa no Paraná, o ProEMI "enquanto oportunidade assim, não adianta, pode pesquisar no país inteiro, o recurso faz diferença sim” (GE).

O recurso financeiro foi um componente essencial para a aquisição de materiais, pequenas reformas e subsídios para a execução de alguns projetos. Nesse sentido, foi possível depreender que muitas das mudanças que ocorreram na escola referem-se a mudanças estruturais. Os laboratórios foram equipados recentemente, a escola "recebeu mais material, recebeu mais recurso, agora a escola conta com lousa digital, conta com data show, com microscópio, tudo isso comprado com o dinheiro desse projeto" (PQ2).

Verbas vinculadas a programas federais, como no caso do ProEMI, sempre foram bem vistas pela comunidade escolar, mas são fontes não estáveis e que em muitos casos estão condicionadas por processos burocráticos (ZIBAS; FERRETTI; TARTUCE, 2005). 
Os discursos sinalizam que as escolas estão passando por um processo de revitalização estrutural e tornando os seus espaços menos precários. É importante destacar que todo recurso financeiro, se bem utilizado pela escola representa, de certa forma, uma melhoria na qualidade de ensino em termos estruturais, mas não se pode afirmar que o mesmo ocorre no processo ensino-aprendizagem, pois muito do que foi adquirido pela escola pode ser que não venha a ser utilizado pelos alunos e professores.

Alguns professores salientam que nada mudou na escola, ou ainda, que não conseguiram observar efetivamente as contribuições do ProEMI. Acreditam que o ProEMI abrange um número pequeno de alunos e as melhorias em termos de ensino-aprendizagem limitam-se aos participantes das ações estabelecidas no contraturno, conforme apontam os excertos a seguir:

\begin{abstract}
"Não, nada, não modificou nada. Inclusive, vou até te fala uma coisa que eu sempre discordei: oficinas com um aluno." (PB5). "Como eu fiquei pouco tempo, eu não consegui visualizar essa mudança para o colégio” (PQ3). “(...) mudanças para a escola foram em termos estruturais, somente, só. (...) não é uma mudança institucional, uma mudança bem pontual, uma mudança para mim professor, só pra mim, no caso, e acrescentou, lógico, pra aqueles meus alunos. Então, é bem restrita esta questão, não houve uma mudança para a escola, houve mudança no seguinte sentido: recebeu mais material. (...). Isso acrescentou, esses equipamentos e tudo mais, agora para a escola como um todo é muito pouco, é muito limitado" (PQ2). "Então a gente vê assim, que na verdade é só, é como se fosse um marketing. Ah! Aquela escola tem ensino inovador, mas o que significa ter ensino inovador? A princípio nada, a princípio nada" (PQ1).
\end{abstract}

A partir destes fragmentos podemos perceber que os efeitos do ProEMI, considerando o contexto da prática nas escolas investigadas, são efeitos de primeira ordem e indicam mudanças na prática e não no sistema como um todo. Não foi possível visualizar impactos no que se refere a mudanças nos padrões de acesso, oportunidades ou justiça social, os quais são considerados efeitos de segunda ordem (MAINARDES, 2006). 
Conforme relato dos professores, um dos maiores desafios foi a dificuldade em manter o aluno participando das ações no contraturno. Houve momentos de evasão em todos os projetos, considerando que vários alunos relataram para os professores que sua saída foi ocasionada por demandas financeiras, como a busca por um emprego, um estágio ou, ainda, o fato de o Programa não oferecer bolsa auxílio para transporte ou para que eles pudessem alimentar-se no horário oposto ao período escolar, atentando para a condição social na qual muitos alunos vivem.

De modo geral podemos concluir que os projetos de contraturno abrangiam uma minoria de estudantes. Em alguns colégios foi realizada uma seleção de quem participaria, dando prioridade para: os melhores alunos; aqueles que precisam de notas em determinadas disciplinas e os que apresentavam um comportamento relativamente aceitável. A grande maioria, porém, apresentava o perfil do aluno que não trabalhava e majoritariamente eram estudantes do diurno, os quais participaram das ações de modo voluntário e estavam dispostos a fazê-lo.

Tais considerações nos levam a pensar que houve casos de exclusão justamente por exigir a presença dos alunos em turnos diferentes das aulas regulares, fazendo com que aqueles que trabalham, ou ainda, os que não possuem condições de se manter no contraturno, devido à ausência de alimentação ou locomoção, ficassem fora dos projetos.

Em que pesem estas fragilidades, os professores relatam que o ProEMI possibilita "compensar a defasagem do Ensino Médio" (PF3), permitindo aumentar o interesse do aluno por determinados assuntos, observando que os projetos no contraturno aumentaram "o estímulo, o despertar, o interesse" dos educandos que participam destas ações (PB3).

Compreendem que é necessário motivar o aluno para que ele tenha gosto pelos estudos. Desse modo, as ações praticadas tiveram como pressuposto o fator motivação e o desejo de possibilitar maior autonomia ao aluno quanto ao seu desenvolvimento intelectual e cognitivo.

O fator motivação, indicado pelos professores, é uma questão que pode ser problematizada mais no sentido de mobilização. Charlot (2012) salienta que o aluno tende a continuar estudando quando encontra não somente sentido na 
escola, mas também quando há prazer nos estudos. Então, a tese que se coloca é baseada em uma equação pedagógica que está além do embate sobre a Pedagogia tradicional e Pedagogia construtivista, conforme indica este autor.

A equação pedagógica que é trazida por Charlot (2012, p. 11) encontra-se na seguinte expressão: "aprender = atividade intelectual + sentido + prazer". Logo, o sucesso no processo ensino-aprendizagem depende mais da mobilização intelectual dos alunos do que motivação. Charlot (2012) argumenta por que devemos pensar em mobilização:

Eu falo de mobilização, não falo de motivação. Eu não gosto da palavra motivação. Porque, muitas vezes, quando se diz que se vai motivar os alunos, trata-se de encontrar uma forma de os alunos fazerem o que eles não estão com vontade de fazer. Isso funciona uma semana, duas semanas e depois nada. O problema não é fazer com que os alunos façam o que eles não estão com vontade de fazer; o problema é fazer nascer um desejo. Motivam-se os outros de fora, mobiliza-se a si mesmo de dentro (p. 11).

Desse modo, mobilizar os alunos é fazer nascer o desejo por aprender e esta é uma questão fundamental em uma atividade intelectual. $\mathrm{O}$ fato de o ProEMI não ser uma proposta cuja finalidade está em alcançar uma determinada nota para poder passar para a série seguinte, pois não há uma avaliação formal, e também por não ser uma atividade obrigatória na grade curricular, possibilitou ao professor mobilizar os alunos, permitiu criar condições para o desejo de aprender, conforme podemos verificar nos excertos a seguir:

"O interesse passou a ser maior, antes eles não tinham muito interesse, era aquela coisa meio na brincadeira e tal e eles começaram a se interessar mais, a buscar mais, a pesquisar. (...) o estímulo, o despertar o interesse pela Biologia. Eles começarem a ver que através do estudo você tem uma série de oportunidades que acabam aparecendo. Eu vejo assim, a diferença, o quanto despertou interesse neles e o quanto eu já tive de resultado com eles por causa do ProEMI" (PB3). "A criação deles, por exemplo, essa peça de teatro, eles criam, eles perguntam, eles têm interesse. Então, quer dizer, isso é inovador dentro do próprio desenvolvimento deles. Então, o aluno desperta, sabe?" (PF3). 
Ademais, em todos os discursos foi possível identificar que os professores levaram em consideração os temas, conteúdos e opiniões oriundos dos alunos, o que sugere que as ações contemplam, em sua maioria, as expectativas dos estudantes. Contemplar as expectativas dos estudantes é privilegiar o protagonismo juvenil, resulta em novos significados do processo de escolarização e constrói uma identificação positiva da escola para com o aluno (ZIBAS; FERRETTI; TARTUCE, 2005). Ainda que estas ações sejam de alcance e direções variadas, mesmo com suas limitações, são iniciativas que merecem ser reconhecidas na trajetória do ProEMI.

Em relação à autonomia do estudante observamos a partir dos relatos dos professores, enquanto discursavam sobre suas práticas pedagógicas, que em determinados momentos estabeleceram-se ocasiões nas quais o aluno teve de tomar decisões diante da proposta de trabalho suscitada pelo projeto, cabendo ao professor apenas conduzir este processo, priorizando o desenvolvimento do estudante. $\mathrm{O}$ espaço escolar do contraturno foi organizado de modo que fosse possível estabelecer esta autonomia, criando um ambiente encorajador para o desenvolvimento de atitudes independentes e investigativas por parte dos educandos.

Essa autonomia do aluno, destacada no processo pedagógico, é subsidiada pela busca da aprendizagem e da reconstrução dos saberes de forma contínua pelo estudante. O professor é visto como mediador deste processo e o aluno torna-se o responsável pela construção do seu conhecimento. O que se observa é uma redefinição do papel do aluno e do professor no processo de ensino-aprendizagem.

Como fator positivo, os professores perceberam que o ProEMI possibilitou, ainda, enriquecer o relacionamento interpessoal entre professor, aluno e colegas de turma, inclusive mudou a forma como o aluno vê o professor, pois "a gente acaba tendo um contato mais íntimo com eles, uma dedicação maior por eles, e eu consigo conversar com relação à higiene, com relação à qualidade de vida, com relação à alimentação, quanto à escrita, quanto ao comportamento social, sabe, quanto ao respeito, quanto ao bullying" (PB2). O aluno passou a entender o papel do professor não apenas como autoridade, mas em suas múltiplas formas de intervir positivamente na construção do seu conhecimento. 
Os alunos que participam das ações propostas no contraturno escolar observam que sua participação pode contribuir em termos de ganho de conhecimentos sobre os diferentes assuntos trabalhados nos respectivos projetos. Muitos deles participam de outros projetos de contraturno além daquele oferecido pelo macrocampo ICP. Alguns alunos destacam que o ProEMI "vai estar contribuindo (sic) para a nossa formação" (A62), bem como "para minha formação cultural" (A65) e dão importância ao fato de suas atividades serem registradas no histórico escolar.

Ressaltam, ainda, que o Programa contribui para fortalecer alguns conhecimentos adquiridos em sala de aula, proporcionando, assim, um melhor aprendizado, bem como o fato de motivar os estudos, "nos ensina coisas inovadoras, coisas novas, interessantes" (A60). Alguns salientam que isto pode colaborar futuramente, demonstrando não saberem ao certo as contribuições do ProEMI para a sua formação.

\section{O ProEmi e o Papel da Inovação no Ensino de Ciências da Natureza}

Para que pudéssemos desvelar as implicações do ProEMI no ensino de Ciências da Natureza optamos por empreender esforços no sentido de investigá-las por meio das abordagens potencialmente inovadoras desenvolvidas no macrocampo ICP. Buscamos compreender, assim, quais e como as ações intencionais foram construídas de modo que pudessem ressignificar o espaço escolar tendo como subsídio a inovação educacional.

Entendemos por inovação educacional uma mudança para melhoria na educação, engendrada de maneira deliberada e consciente pelos atores envolvidos no processo educacional e por isso é condicionada por ideologias e relações de poder no controle do conhecimento (CARBONELL, 2002). Pode envolver mudanças nos modelos e práticas pedagógicas, nos conteúdos, na cultura escolar e modificar atitudes e ideias. As inovações no contexto das escolas podem ser externamente induzidas ou, ainda, podem ser internamente geradas, resultando em inovações no interior deste contexto (FARIAS, 2006; CARBONELL, 2002). 
Desse entendimento, propomo-nos a analisar o ProEMI como uma proposta de inovação externamente induzida e as práticas pedagógicas no âmbito do Programa como sendo inovações internamente geradas com o propósito de resolver problemas no contexto escolar.

Ramos (2011), ao fazer uma leitura sobre as proposições que norteiam o ProEMI, afirma que incentivar a inovação curricular na direção tomada pelo Programa é um fato a ser considerado como positivo, pois as práticas pedagógicas conformadas pela inovação seriam formas de dinamizar o processo de ensino-aprendizagem. Partindo desse pressuposto é que conferimos um olhar sobre as abordagens inovadoras no ensino de Ciências da Natureza, apontando para as suas implicações.

De modo a sistematizar as abordagens potencialmente inovadoras que foram disseminadas no âmbito do macrocampo ICP, elaboramos o Quadro 2 para que, assim, fosse possível visualizar algumas das ações estabelecidas no contraturno nos nove colégios participantes da pesquisa.

O Quadro 2 apresenta uma sucinta descrição das ações realizadas no contraturno escolar, o qual foi construído com base nos relatos dos professores do ProEMI e tendo como suporte os projetos de ICP. As abordagens trazem uma série de implicações que serão tratadas a seguir por meio de proposições, as quais enfatizam, entre a estagnação e os avanços, a necessidade de repensarmos a formação dos professores, o currículo e as práticas pedagógicas desenvolvidas no Ensino de Ciências. 


\section{Quadro 2 - Abordagens potencialmente inovadoras}

\begin{tabular}{|c|c|c|c|}
\hline Oferta & Temáticas & Disciplinas & Algumas Ações \\
\hline Oficina & Robótica & $\begin{array}{l}\text { Física/ } \\
\text { Matemática }\end{array}$ & $\begin{array}{l}\text { Montagem e programação de robôs usando kit de ro- } \\
\text { bótica educacional. Foi possível trabalhar, entre outros } \\
\text { aspectos, cálculos, simetria, equilíbrio, etc. Envolveu } \\
\text { alunos em pesquisas orientadas. }\end{array}$ \\
\hline Disciplina & $\begin{array}{l}\text { Robótica } \\
\text { e Astrono- } \\
\text { mia }\end{array}$ & Física & $\begin{array}{l}\text { Montagem e programação de robôs usando kit de } \\
\text { robótica educacional e oficina de astronomia com es- } \\
\text { tudo sobre radiação, forças de interação, etc. Envolveu } \\
\text { alunos em pesquisas. }\end{array}$ \\
\hline Projeto & $\begin{array}{l}\text { Química do } \\
\text { esporte }\end{array}$ & Química & $\begin{array}{l}\text { Envolveu a Química de uma maneira geral e sua relação } \\
\text { com a prática desportiva. Foi possível trabalhar a parte } \\
\text { do metabolismo e alimentação saudável, bem como os } \\
\text { transtornos alimentares. }\end{array}$ \\
\hline Projeto & $\begin{array}{l}\text { Química } \\
\text { das tintas }\end{array}$ & Química & $\begin{array}{l}\text { Trabalho que envolveu experimentação e pesquisa, } \\
\text { manipulação de corantes alimentícios, técnicas de ex- } \\
\text { tração de corantes de plantas. Realização de trabalhos } \\
\text { artísticos com os alunos. }\end{array}$ \\
\hline Projeto & Nutrição & Biologia & $\begin{array}{l}\text { Nutrição e desenvolvimento corporal. Foi possível } \\
\text { trabalhar aspectos relacionados à alimentação saudável } \\
\text { e os transtornos alimentares, etc. Envolveu alunos em } \\
\text { pesquisas. }\end{array}$ \\
\hline Disciplina & $\begin{array}{l}\text { Fotografia } \\
\text { científica }\end{array}$ & Biologia & $\begin{array}{l}\text { Trabalho que envolveu aspectos relacionados à fotogra- } \\
\text { fia científica a partir do histórico da fotografia, como } \\
\text { manusear a máquina fotográfica, criar um banco de } \\
\text { imagens e divulgar em fotolog. }\end{array}$ \\
\hline Projeto & $\begin{array}{l}\text { Meio am- } \\
\text { biente }\end{array}$ & Biologia & $\begin{array}{l}\text { Debates em torno da temática meio ambiente e qua- } \\
\text { lidade de vida. }\end{array}$ \\
\hline Oficinas & $\begin{array}{l}\text { Aulas prá- } \\
\text { tic as de } \\
\text { modo geral }\end{array}$ & $\begin{array}{l}\text { Química/ } \\
\text { Biologia/ } \\
\text { Física }\end{array}$ & $\begin{array}{l}\text { Ênfase na relação teoria/prática com o uso do } \\
\text { laboratório de Ciências da escola. Envolveu uso das } \\
\text { TICs e temáticas diversas do cotidiano do aluno. }\end{array}$ \\
\hline
\end{tabular}

Fonte: As autoras, 2015. 


\section{Proposição 1: A Interdisciplinaridade e a Contextualização Foram Basilares no que se Refere à Forma de Abordar os Saberes Escolares no Ensino de Ciências da Natureza}

Ao realizarmos a análise dos relatos dos professores de Ciências da Natureza, bem como as considerações expostas nos projetos de ICP, foi possível depreender determinada prioridade em práticas pedagógicas que consideravam o cotidiano e a realidade dos educandos, indicando que houve intenção de contextualizar os conhecimentos científicos. A prática interdisciplinar também é referenciada em alguns projetos, entendendo a necessidade de interligar múltiplos saberes:

“(...) fundamentando a execução de projetos científicos, envolvendo investigações de caráter interdisciplinar, inspiradas em temas oriundos da curiosidade e do cotidiano do aluno” (C2). "(...) você tem que contextualizar seu ensino e o laboratório é um ambiente muito útil nesse sentido" (PQ3). "Desenvolver práticas simples onde o aluno perceba a presença da Química no seu dia a dia; perceber que o dia a dia do aluno é envolvido por muitos conceitos teóricos e práticos químicos; (...) Interpretar e saber usar os conceitos teóricos com a vida prática do aluno" (C9). "Trabalhar com conteúdos de diversas disciplinas, não fragmentados e associados a situações reais da vida moderna” (C7).

A contextualização e a interdisciplinaridade são consideradas eixos organizadores do currículo, conforme a LDB 9.394/96, e, apesar de não ser novidade em termos de proposições curriculares, foram amplamente discutidas nas primeiras diretrizes curriculares de 1998 e disseminadas nos PCNEM (BRASIL, 2000). Consideramos estes elementos como uma tendência pedagógica que assumiu essencial destaque na escola a partir desses textos legais.

Lopes (2002) destaca que o processo de apropriação do discurso curricular sobre a contextualização disseminado nos PCNEM recebeu um caráter ambíguo e híbrido, ${ }^{4}$ pois englobou matrizes teóricas distintas na intenção de

${ }^{4}$ O discurso curricular híbrido é abordado por Lopes (2002) com base nas ideias de Stephen Ball, nas quais o autor discute que tendências teóricas distintas são incorporadas nas políticas de currículo no sentido de legitimar o discurso, ou seja, mesclas de diferentes teorias são disseminadas em textos oficiais, proporcionando diversos sentidos, no entanto alguns são apropriados com maior 
legitimar no contexto escolar a ideia de contextualização. Cabe, então, desvelarmos o sentido atribuído ao conceito de contextualização que permeia a prática pedagógica dos professores investigados, pois tais sentidos trazem implicações pedagógicas no processo ensino-aprendizagem em Ciências da Natureza.

Como foi possível perceber nos trechos expostos anteriormente, as palavras "dia a dia e cotidiano" são usadas de modo amplo e indicam valorização das situações concretas da vida dos alunos em sintonia com os saberes escolares (LOPES, 2002).

É possível, contudo, identificar que contextualizar, para alguns dos professores de Ciências investigados, significa partir de contextos nos quais é possível a aplicação dos conhecimentos científicos. Dessa concepção decorre a centralidade na importância do conteúdo científico na vida do aluno, implica conceber o processo ensino-aprendizagem pautado principalmente na utilidade dos conceitos científicos no cotidiano do aluno (SANTOS, 2007).

Conforme Lopes (2002), este sentido atribuído ao conceito de contextualização distancia-se de uma perspectiva crítica de currículo. Para isso, o conceito de cotidiano deve ser aprendido em um sentido mais político-social, que envolve um estudo que vá além dos conceitos científicos. Santos (2007) defende que para o exercício da cidadania, a contextualização deve abarcar assuntos centrados em aspectos econômicos, ambientais, políticos, éticos e sociais relacionados aos temas científicos presentes na sociedade.

É importante destacarmos que alguns professores apresentam uma perspectiva mais abrangente sobre a contextualização. O sentido de contextualização foi o de estabelecer relações entre os conteúdos e o contexto social e político-cultural no qual os alunos estão inseridos.

intensidade e outros em menor proporção ou ainda podem ser negados. A intenção é, em todo caso, obter consenso sobre o discurso oficial. Lopes (2002) também baseia-se nas teorizações de Néstor García Canclini sobre culturas híbridas. Para Lopes (2002), o hibridismo é intrínseco ao conceito de recontextualização, referenciado na teoria sobre o discurso pedagógico de Basil Bernstein. 
A ideia de que deve haver contextualização dos conhecimentos biológicos, físicos e químicos é congruente com a asserção realizada por Cachapuz, Praia e Jorge (2004) ao sinalizarem a necessidade de trabalhar a Ciência a partir de uma dimensão contextualizada, considerando situações de vivências dos alunos que podem ser incluídas como objetos de estudos pelos alunos.

A interdisciplinaridade foi assumida pelos professores como um princípio integrador, entendida por estes interlocutores como sendo uma forma de interação entre as disciplinas escolares. Segundo Lenoir (1998), diante das várias possibilidades de interação entre as disciplinas, dentro de um plano epistemológico, a interdisciplinaridade no contexto escolar pode ser assumida como abordagem relacional ou como uma abordagem radical.

A interdisciplinaridade como abordagem relacional tende a estabelecer relações entre as disciplinas no sentido de complementaridade, convergência ou interconexões. Já como abordagem radical envolve a ideia de um currículo global que abrange enfoques temáticos e conceituais variados (LENOIR, 1998).

Nesse sentido, destacamos que a interdisciplinaridade no contexto escolar investigado apresentou-se como uma abordagem relacional, cuja finalidade foi a complementaridade entre algumas disciplinas. Isto implica conceber a interdisciplinaridade como elemento que favorece, sobretudo, o processo de aprendizagem dos alunos, pois busca compreender os fenômenos a partir de vários pontos de vista.

Das considerações feitas em torno da interdisciplinaridade e da contextualização podemos inferir que estas abordagens apresentam-se como elementos potencialmente inovadores, pois, de fato, podem ter dinamizado as práticas pedagógicas estabelecidas no contraturno escolar. A partir dessas abordagens foi possível observar que, em algumas das ações no contraturno, os professores de Ciências da Natureza contemplaram contextos sociais mais abrangentes em destaque na sociedade, possibilitando integrar alguns conhecimentos no sentido de ressignificá-los. 


\section{Proposição 2: As aulas práticas são apontadas como uma das principais formas de possibilitar uma abordagem inovadora no Ensino de Ciências, tendo em vista que a maioria dos projetos teve como suporte o desenvolvimento de ações pautadas em aulas práticas}

A maioria dos projetos de ICP destaca como estratégia de trabalho a inclusão de abordagens essencialmente práticas sugerindo a sua importância e sua articulação com os conteúdos abordados nos projetos. Estas considerações estão alicerçadas na ideia da necessidade de articulação entre teoria e prática, como proposto no macrocampo ICP.

Em alguns projetos de ICP são elencados determinados conteúdos que foram trabalhados no decorrer do desenvolvimento da proposta, bem como os espaços escolares e extraescolares aproveitados para as aulas práticas. A ênfase, em virtude da utilização dos espaços escolares, recai sobre o uso do Laboratório de Ciências e o de Informática, sendo previstas, ainda, algumas saídas de campo estabelecendo momentos pedagógicos fora da escola, como visitas a observatórios astronômicos e pesquisas de campo.

De certo modo, utilizar o Laboratório de Ciências da escola motivou alguns professores a darem ênfase às aulas práticas em suas propostas pedagógicas no contraturno. Esta escolha também está associada às motivações pessoais do professor, derivada da experiência formativa positiva quanto ao uso da experimentação nos processos educacionais de Ciências da Natureza.

As aulas práticas que assumem destaque no Laboratório de Ciências apresentam um caráter experimental. Em várias das escolas que investigamos o Laboratório de Ciências apresenta-se equipado com materiais que permitem a realização de experimentos simples e que dão conta das necessidades mais emergentes em torno da aprendizagem do aluno a partir da relação teoria-experimento no EM. 
Destacamos que, em algumas escolas, o recurso alocado pelo ProEMI possibilitou a aquisição de materiais que contribuíram nesse sentido. Já as aulas práticas que necessitaram do Laboratório de Informática tiveram alguns percalços, tais como a ausência de computadores para todos os alunos e a necessidade de manutenção dos equipamentos.

Algo que teve impacto positivo na escola com a vinda do ProEMI foi o entendimento por parte dos professores de que as atividades experimentais podem ser realizadas em espaços que vão além das paredes da escola, pois em várias das ações estabelecidas no contraturno constatamos a diversidade de atividades em contextos variados, como o entorno escolar, visitas a parques e exposições, entre outros locais. A seguir apresentamos algumas dessas ações:

\begin{abstract}
“(...) levar em lugares que fossem úteis para eles, para tentar perceber, assim, esta questão artística e que fosse relacionada à Química. (...) o primeiro que eu levei foi à Vila Velha. Por quê? Porque tem o arenito, poderia trabalhar a constituição do próprio arenito, a vegetação, fala da parte biológica, porque lá tem estagiários de Biologia que falam desta questão. Tem umas pinturas muito antigas (...). A segunda, que a gente fez, foi uma exposição do Leonardo da Vinci, que estava tendo no shopping, que falava mais da parte do maquinário e não da parte artística, e aí, eu chamei a professora de matemática para ela me ajudar e falar do Leonardo da Vinci e tudo, e integra com os aspectos da matemática, então mostra, digamos, o pintor e o outro lado matemático dele. (...) o terceiro lugar que eu levei, foram as grutas do Bacaitava em Colombo" (PQ2). "A gente participou da Olimpíada de Astronomia e uma das etapas era a mostra de foguetes, daí a gente preparou o foguete e foi lá no Centro Politécnico (UFPR) para fazer o lançamento. Nós passamos a tarde lá” (PF1).
\end{abstract}

Proporcionar momentos como estes nas escolas pode contribuir para ressignificar o currículo do EM, pois apresentam significativo valor pedagógico, desde que estas ações não sejam vistas como simples alterações da rotina, ou, ainda como forma de sanar as curiosidades dos alunos e professores, devendo ser desenvolvidas de forma planejada com o objetivo de aprofundar questões relevantes para o desenvolvimento intelectual, moral e político do estudante (SILVA; MACHADO; TUNES, 2011). 
Como foi possível constatar nos depoimentos, as experiências externas ao contexto escolar englobaram discussões referentes às áreas de conhecimento e que podem ter contribuído de forma significativa para o processo ensino-aprendizagem. Incluir situações que permitem trabalhar os conceitos científicos fora da sala de aula por meio da experimentação dos fenômenos é romper com práticas educativas estabelecidas historicamente, promovendo mudanças profícuas nelas. Para Delizoicov, Angotti e Pernambuco (2002):

Trazer o mundo externo para dentro da escola, possibilitar o acesso a novas formas de compreendê-lo, as suas questões candentes, faz parte dessa alimentação. Propiciar o novo em Ciências Naturais é trazer para o ambiente escolar: as notícias de jornal, as novidades da Internet, é visitar museus e exposições de divulgação científica, como parte da rotina da vida escolar (p. 153-154).

Nesse sentido, o ProEMI oportunizou o estabelecimento de relações que garantem uma perspectiva mais abrangente sobre o conhecimento científico, garantindo momentos prazerosos e que trazem sentido aos estudos, os quais são indispensáveis para suscitar no aluno o gosto pela aprendizagem no ensino de Ciências da Natureza. Para que essas inovações não caiam no vazio, no entanto, e não sejam vistas como mudanças superficiais, tais considerações deveriam fazer parte da rotina da vida escolar e não apenas em momentos oportunos como fim do ano letivo, como premiação por bons resultados em avaliações ou em projetos de contraturno escolar.

\section{Proposição 3: Abordar o Ensino de Ciências de forma inovadora significa privilegiar a experimentação, na qual é possível trabalhar aspectos da natureza da Ciência e a relação entre teoria e prática}

Observamos que, na concepção dos professores investigados, a experimentação auxilia na compreensão dos conhecimentos escolares e tem sido usada como uma estratégia de ensino e aprendizagem, o que é coerente com as proposições de Cachapuz, Praia e Jorge (2004), segundo as quais o Ensino de Ciências deve ser experimental. Nos discursos de alguns professores sobre 
a utilização das aulas práticas, no entanto, com ênfase na experimentação no Ensino de Ciências, percebemos que esta funciona como uma situação de confrontação entre teoria e prática, revelando um caráter simplista da experimentação (GALIAZZI; GONÇALVES, 2004), sugerindo que a atividade experimental é condição fundamental para uma melhor compreensão do conteúdo trabalhado e uma forma de relacionar teoria e prática:

\begin{abstract}
“(...) então a gente podia ver, fazer uma aula teórica e ir para o laboratório fazer a prática e depois discutir com eles” (PQ3). “(...) quando a gente começou com a ideia do projeto de iniciação científica era justamente testar as aulas práticas. Tudo o que é livro de Biologia, de Ciências, ele traz uma série de aulas práticas. Então, a gente fez um levantamento primeiramente aqui na biblioteca, o que é que tinha de aula prática e eu pedi para que eles escrevessem as que eles mais se interessavam. Então a gente separou uma série de aulas. Depois que a gente separou as aulas a gente começou a testar: vamos ver se realmente dá certo essa prática. Eles pesquisaram na Internet algumas aulas e fazendo, eles foram vendo as dificuldades encontradas. Terminava aquela prática, eu fazia uma aula teórica com eles, a gente montava um relatório e perguntava: O que deu certo? O que não deu certo? Por que não deu certo?" (PB3).
\end{abstract}

Destes trechos podemos concluir que as atividades práticas no laboratório têm servido para testar a previsibilidade da teoria. Embora se considere que exista um caráter investigativo nesta ação, é comum a ideia entre professores de que a atividade experimental tem a função de concretizar para o aluno as formulações teóricas da Ciência e que, desse modo, estariam facilitando a aprendizagem (SILVA; MACHADO; TUNES, 2011). Ainda podemos observar, nestes relatos, certo distanciamento entre teoria e prática nas aulas de Ciências. Nesse caso, tais elementos são trabalhados em momentos diferentes. Outra asserção que corrobora esta ideia pode ser dada pelo seguinte depoimento:

Eu acho que esse tempo que você dedica a uma prática efetiva, sem a preocupação do teórico, porque ela já tem a aula teórica, o plano curricular já tá sendo cumprido, então, você sabe que aquela aula é algo prático, algo interessante, algo que o grupo gosta de estar trabalhando, de estar pesquisando (PB1). 
Constatamos que a própria noção do professor PB1 sobre a construção do conhecimento deslocada da teoria e com ênfase na prática faz com que o processo ensino-aprendizagem se reduza a um procedimento mecânico. Nesse caso, ir além de uma perspectiva de ensino que é tradicionalmente abordada em sala de aula significa restringir o saber a sua dimensão prática, sugerindo a exclusão de sua dimensão teórica, que naquele momento já havia sido supostamente tratado, no que o professor destaca ser o plano curricular.

Compreendemos que teoria e prática são conceitos indissociáveis (CARBONELL, 2002) e separá-los é negar a possibilidade de reflexão e compreensão dos fenômenos químicos, físicos e biológicos aos alunos.

É importante destacarmos que a atividade experimental não deve ter a função de concretizar a teoria, isto é um equívoco, conforme argumentam Silva, Machado e Tunes (2011). Nas atividades em laboratório cuja ideia central é o seu caráter reprodutivista e comprobatório a visão que sobressai "é a da experimentação empirista do fazer para extrair a teoria, com uma abordagem tradicional do demonstrar para crer", e isto é pautado na concepção de Ciência objetiva, neutra, que tem apoio em teorias surgidas da mera observação do fenômeno (GALIAZZI; GONÇALVES, 2004, p. 326).

Alguns professores manifestam como um dos princípios que devem ser trabalhados nas aulas práticas: o ato de abordar a Ciência, como se faz Ciência, ou ainda, instrumentalizar os alunos para a Ciência. O método científico e sua relação direta com a experimentação foram apontados como metodologia precursora dentro de alguns projetos, demonstrando haver concepções ingênuas sobre a natureza da Ciência. Apenas um professor expressou claramente a concepção de que trabalhar no macrocampo ICP trata-se de tentar "introduzir aspectos da Ciência e não a própria Ciência” (PQ2).

Quando um dos professores salienta: “(...) então a gente poderia ver, fazer uma aula teórica e ir para o laboratório fazer a prática (PQ3)", este manifesta a condição de que a prática é necessária para confirmar a teoria, a qual é precedida pela observação, o que caracteriza uma lógica empirista e indutivista da natureza do trabalho científico. Corroborando com esta concepção, o professor PQ4 observa: 
"Na minha concepção eu tenho que instrumentalizar os alunos para lidar um dia com a Ciência. Ciência da Natureza, Ciência, sempre, como eu falei, trabalhando com a questão do método científico, as hipóteses, achar um problema, tentar achar soluções e daí instrumentalizar na questão de manuseio de equipamentos de laboratório, microscópio, pipetagem, essas coisas todas de laboratório" (PQ4).

Este depoimento reflete a ideia de que o trabalho científico requer uma sequência padronizada de procedimentos e etapas sucessivas como: observar, coletar dados, elaborar hipóteses, realizar constatações e a partir da experimentação chegar a conclusões por meio de um processo indutivo. Isto caracteriza uma concepção de Ciência de cunho empirista-indutivista, apoiada na observação e na atividade experimental, cuja realização está a cargo de indivíduos isolados, que utilizam o método científico para a produção de conhecimentos. O seguinte depoimento vai ao encontro desta concepção:

"Eu gosto de fazer uma experiência, eu começo explicando, vamos dizer, como que é o desenvolvimento de um pesquisador dentro de um trabalho, então ele começa lá, observação, depois medida, tabula as medidas, faz gráfico, interpretação do gráfico e a equação final. Então, a gente trabalha com esse encaminhamento, para dar uma noção de verdade das pesquisas, e eles gostam, porque é uma coisa bastante clara para eles, como que é o caminhar da Ciência (...)" (PF3).

A História, Filosofia e Sociologia da Ciência têm contribuído e tematizado sobre a concepção de Ciência empirista/indutivista há algum tempo. Há sem dúvida a prevalência desta concepção entre os docentes da área, "isto possivelmente decorre da ausência, durante a formação inicial, de discussões epistemológicas que poderiam contribuir para a compreensão da complexidade na construção dos fatos científicos" (SCHEID; FERRARI; DELIZOICOV, 2007, p. 157).

A experimentação é um momento interessante para se trabalhar a natureza da Ciência com os alunos, por isso, segundo Hodson (1994), é preciso pensar em um modelo de Ciência que seja válido filosoficamente, o qual não seja baseado no indutivismo e sim um modelo de Ciência em que se reconheça minimamente a falibilidade e dependência teórica durante observação dos 
fatos, de considerar que a Ciência não é neutra e que esta recebe influência de fatores socioeconômicos, políticos, éticos e morais. É importante que durante a experimentação isto seja superado no contexto das inovações curriculares para que assim se possa progredir em termos de qualidade no Ensino de Ciências.

A concepção de Ciência, que permeia a ação dos professores de Ciências, tem profundas implicações na forma como eles a ensinam. Cachapuz, Praia e Jorge (2004) destacam a necessidade de os professores de Ciências fundamentarem suas práticas didático-pedagógicas em uma visão pós-positivista da Ciência. Subjacente a esta visão encontra-se a ideia de que o método científico não é universal, que a Ciência é uma construção humana dentro de um projeto social culturalmente contextualizado e, portanto, é parte da nossa tradição intelectual, social e cultural (CACHAPUZ; PRAIA; JORGE, 2004).

Isso confere à Ciência o caráter de não neutralidade e que esta não é uma obra de gênios isolados que não interagem e não realizam intercâmbios com outros pesquisadores. A Ciência é ao mesmo tempo uma atividade individual e coletiva, por isso é preciso superar esta visão individualista na construção do conhecimento científico (CACHAPUZ et al., 2011).

Dessas considerações, compreendemos que para inovar no

(...) ensino de ciências precisamos não só de uma renovação epistemológica dos professores, mas que essa venha acompanhada por uma renovação didático-metodológica de suas aulas. Agora não é só uma questão de tomada de consciência e de discussões epistemológicas, é também necessário um novo posicionamento do professor em suas classes para que os alunos sintam uma sólida coerência entre o falar e o fazer. Este é um ponto bastante complexo, pois os professores para o desenvolvimento de suas aulas necessitam de materiais instrucionais coerentes com uma proposta de ensino com investigação (CACHAPUZ et al., 2011, p. 10).

Uma das tendências na atualidade em termos de experimentação encontra-se no ensino experimental com enfoque investigativo (SILVA; MACHADO; TUNES, 2011; CACHAPUZ et al., 2011; CARVALHO, 2013). Segundo Cachapuz et al. (2011), o ensino por investigação apresenta-se como uma es- 
tratégia de ensino-aprendizagem em Ciências que permite a (re)construção do conhecimento mediante um processo de investigação orientada por situações problemáticas de interesse.

Desse modo, propor situações problematizadoras oportunizando a dialogicidade e a capacidade de reflexão entre os alunos para que estes possam trazer soluções para os problemas expostos contribui para uma atmosfera de investigação.

Delizoicov, Angotti e Pernambuco (2002) propõem, com base em Paulo Freire, uma perspectiva pedagógica que pode ser apropriada pelo professor no que se refere à experimentação com enfoque investigativo. Tal perspectiva é baseado em temas geradores que valorizam os alunos em seu processo de aprendizagem, privilegiando a sua realidade social. Os temas geradores são considerados objeto de estudo que relacionam "o fazer e o pensar, o agir e o refletir, a teoria e a prática” e são organizados em três momentos pedagógicos: estudo da realidade, organização do conhecimento e aplicação do conhecimento ${ }^{5}$ (DELIZOICOV; ANGOTTI; PERNAMBUCO, 2002, p. 165).

Consideramos que uma proposta pedagógica dessa natureza pode propiciar um papel inovador no que se refere à experimentação no Ensino de Ciências, permitindo um melhor desenvolvimento das aulas práticas estabelecidas no âmbito do ProEMI.

Da análise depreendida em nossa investigação, foi possível constatar a preocupação que os interlocutores têm em relação à integração entre teoria e prática. Tal inquietação apareceu de forma especial no contexto de produção de texto do ProEMI, analisado a partir do documento orientador em ambas as versões de 2013 e nos projetos de ICP.

Os professores investigados vêm se esforçando para que essa articulação aconteça, entretanto, conforme discutimos nesta proposição, ainda há que se avançar em termos de compreensão e de materialização do que vem a ser esta

5 Para saber mais sobre os três momentos pedagógicos consulte a obra dos autores em: DELIZOICOV, D.; ANGOTTI, J. A. P.; PERNAMBUCO, M. M. C. A. Ensino de ciências: fundamentos e métodos. São Paulo: Cortez, 2002. 
articulação em sala de aula, a qual vem se apresentando de forma dicotômica e não como unidade. É necessário, ainda, atentar para a criação de espaços de formação nos quais os professores possam dialogar sobre a natureza da Ciência, conhecendo os principais epistemólogos e suas teorias do conhecimento, refletindo, discutindo e confrontando-as para que possam aprofundar as "suas próprias concepções e daí retirando indicações, orientações e ensinamentos quanto às estratégias, métodos e procedimentos a adotar no seu trabalho docente" (PRAIA; CACHAPUZ; GIL PÉREZ, 2002, p. 129).

\section{Proposição 4: Abordar o ensino de Ciências da Natureza de forma inovadora significa evitar um ensino conteudista e possibilitar um ensino com pesquisa}

$\mathrm{Na}$ análise dos dados foi possível depreender discursos que emergem em direção à ideia de ruptura com um ensino conteudista. Assim, evitar uma quantidade imensa de conteúdos, os quais muitas vezes não fazem sentido para os alunos, é uma preocupação presente nas ações realizadas pelos professores de Ciências do ProEMI.

Em detrimento de um ensino conteudista, encontra-se a possibilidade de desenvolver uma prática didático-pedagógica delineada pela pesquisa, discurso este depreendido, de modo particular, no contexto de produção de texto do ProEMI. Tal proposição foi feita com base nos projetos de ICP e no documento orientador em ambas as versões de 2013.

Nesse sentido, destacamos que as ações estabelecidas dentro do macrocampo ICP tiveram como metas, de modo geral, proporcionar aos educandos o contato com a cultura científica, para que estes pudessem desenvolver maior interesse pela pesquisa científica e "pela busca do conhecimento científico" (C5).

De certa forma, a intenção foi possibilitar "hábitos de investigação e pesquisa" $(\mathrm{C} 2)$. Assim, o incentivo à pesquisa foi apontado como uma forma de articular a construção do conhecimento pelo educando, portanto tal perspectiva poderia servir de base para o processo de ensino e aprendizagem. A pesquisa 
foi entendida como "um processo de construção do conhecimento e quando realizada dentro do método científico, passa a ser chamada de pesquisa científica, fundamentando a execução de projetos científicos" (C2).

Tais projetos de ICP manifestam como intenção o envolvimento do educando em momentos pelos quais é possível "desenvolver um trabalho de caráter investigativo, teórico experimental, abrangendo conceitos nas diversas áreas" (C5) e incentivando a pesquisa por meio da metodologia da problematização, sendo entendida como princípio educativo (C3), bem como estimular "os alunos para a pesquisa e aplicação prática dos conceitos científicos aprendidos" (C5).

Segundo os gestores federais, o macrocampo ICP deve possibilitar o desenvolvimento de uma atitude científica por parte dos educandos, tentando aproximá-los do modo como a Ciência é produzida e como, culturalmente, esta vem sendo integrada na sociedade.

Ainda conforme os gestores federais, esse macrocampo visa a apoiar a integração entre teoria e prática, tendo a pesquisa experimental como atividade capaz de orientar a construção do conhecimento, podendo ser trabalhada nos laboratórios de Ciências ou em outros espaços que possibilitem a pesquisa envolvendo a experimentação de modo sistematizado, tendo em vista o "aprofundamento e a investigação organizada sobre fatos, fenômenos e procedimentos" (BRASIL, 2013b, p. 17). Os gestores federais entendem que desse modo é possível trazer qualidade aos processos formativos dos educandos.

Baseado na proposição de que as atividades desenvolvidas no âmbito ProEMI tenham como pressuposto a pesquisa, estas ganham um caráter de cunho científico, o que indica a aplicação de metodologias de pesquisa. Referente a esta asserção, os gestores federais compreendem que existem diferentes formas de produção de conhecimento e, assim, diferentes metodologias para a sua sistematização, o que confere uma visão de Ciência em sintonia com a ideia de que o método científico passa a ser uma das alternativas para pesquisa e não como única possibilidade. Além disso, sugere uma ótica ampliada do conhecimento científico. 
Infelizmente o discurso em torno da pesquisa, esta entendida como princípio pedagógico com base nas DCNEM (BRASIL, 2012), encontra-se ainda no contexto de produção de textos.

A ideia de ensino com pesquisa em sala de aula, considerando o contexto da prática nas escolas investigadas, é simplista e se refere basicamente a oportunizar o acesso dos alunos às pesquisas realizadas nas universidades, buscar informações em livros, sites de busca na Internet e utilizar esta informação para compreender um determinado conceito científico ou fenômeno natural.

Entendemos que o ensino com pesquisa é uma abordagem inovadora que ainda não foi apropriada por alguns professores, o que sinalizou dificuldades em proporcionar um ensino com pesquisa, o qual tinha sido previsto inicialmente nos projetos de ICP. Como muitos dos projetos não foram elaborados pelos professores, é possível afirmar que tal intenção ficou apenas no plano simbólico.

Conforme Moraes, Galiazzi e Ramos (2004, p. 10), a pesquisa em sala de aula pode ser entendida como um movimento dialético capaz "de envolver os sujeitos, alunos e professores, num processo de questionamento de verdades implícitas nas formações discursivas, propiciando, a partir daí, a construção de argumentos que levem a novas verdades". Dessa compreensão temos o pressuposto de que a realidade não é algo pronto e acabado e sim um processo que é construído pela humanidade.

Embora não possamos afirmar a ocorrência da consolidação de uma cultura de pesquisa em sala de aula, há manifestações em torno da sua inclusão em função das propostas de projetos de ICP e, em decorrência, das proposições colocadas pelo ProEMI no macrocampo ICP. Para Carvalho e Gil Pérez (2001), é difícil que o docente consiga orientar a aprendizagem dos alunos como construção do conhecimento científico por meio da pesquisa se este professor não possuir vivência de uma tarefa investigativa. É necessário, portanto, preparar teoricamente e metodologicamente os professores que queiram trabalhar com esta abordagem inovadora em sala de aula, atentando para uma formação inicial/ continuada como professor pesquisador. 
Para Maldaner (2006, p. 30), o professor pesquisador é aquele que tem como principal característica a capacidade de refletir criticamente a respeito de sua prática, é aquele capaz de ver "a sua realidade de sala de aula para além do conhecimento na ação". Trata-se, assim, de conceber o trabalho docente como compromisso com a disseminação de um saber crítico perante a necessidade de mudança e transformação social.

\section{Considerações Finais}

A partir dessa investigação foi possível constatar que o ProEMI possibilitou momentos de aprendizagem em contextos externos à escola, como museus, parques, entre outros, entendendo que a formação integral do estudante não acontece apenas entre quatro paredes, mas na interação com outras esferas que compõem a sociedade (DELIZOICOV; ANGOTTI; PERNAMBUCO, 2002).

Destacamos que os efeitos do ProEMI nas escolas investigadas foram de primeira ordem, caracterizados por mudanças apenas nas práticas fora da sala de aula e na estrutura parcial da escola (MAINARDES, 2006). Pouca coisa mudou em relação ao currículo, à avaliação, aos padrões de acesso ou oportunidades, por exemplo, com estas mudanças sendo restritas e privilegiaram poucos alunos.

Pudemos observar que as escolas, os professores, os alunos e os gestores, embora ainda estejam vivenciando uma fase inicial do Programa, este tem sido considerado pelos interlocutores como uma proposta que pode permitir ir além do ensino tradicional, oportunizando novas práticas que possibilitam ao aluno a construção do conhecimento de forma significativa.

As abordagens potencialmente inovadoras, estabelecidas no contexto da prática das escolas investigadas, indicaram um movimento de melhoria na qualidade no ensino de Ciências da Natureza. Estas inovações correspondem à participação ativa dos alunos na escolha de temáticas de interesse que trazem à dimensão pedagógica a possibilidade de: difusão e introdução de temas contemporâneos; de o professor trabalhar metodologicamente, incorporando aspectos interdisciplinares; de um ensino contextualizado; do uso do laboratório de modo a priorizar a experimentação em detrimento dos conteúdos (CACHAPUZ; 
PRAIA; JORGE, 2004). Neste último caso, foi preciso atentar para a natureza do trabalho científico, em que constatamos visões ainda empiristas-indutivistas entre os professores de Ciências, sendo que há muito a literatura da área vem criticando esta visão de Ciência (GIL PEREZ et al., 2001).

Discutimos que se a experimentação for disseminada a partir de uma perspectiva de investigação priorizando a unidade teoria-prática, esta pode realmente contribuir para inovar na escola (SILVA; MACHADO; TUNES, 2011; CARVALHO, 2013).

De modo geral, é possível considerar que houve mudanças na prática e na concepção pedagógica do professor de Ciências da Natureza em relação às atividades elaboradas no contraturno, proporcionadas pela adesão do ProEMI na escola. Só que esse fato não alterou a forma como o professor trabalha em sala de aula, pois há uma série de limitações que impedem que o processo de inovação aconteça.

Ao se reportarem às dificuldades que tiveram para executar suas práticas inovadoras, os professores revelam os esforços que vêm fazendo para que o Ensino de Ciências seja renovado, contudo acreditamos que a intenção de mudança nas escolas estaduais investigadas, via política educacional e por meio de inovações nas práticas pedagógicas desenvolvidas no contraturno escolar, só será efetiva se houver um movimento para inovação de modo a romper com o ensino tradicional em sala de aula, sendo assumida não como atividades extracurriculares e sim impactando a forma como o professor atua didático-pedagogicamente nesse espaço escolar.

Como foi possível perceber, há uma cultura para a inovação no ensino de Ciências da Natureza lançada especificamente pelo programa investigado na rede pública estadual de ensino em Curitiba - PR. Por outro lado, o que acontece efetivamente é uma mudança superficial, uma mudança epidérmica, atrelada às inovações que não impactaram o ensino em sala de aula, pois tais ações ocorrem apenas no contraturno, privilegiando poucos alunos (FARIAS, 2006; CARBONELL, 2002). 
Consideramos importante atentar para essa dinâmica de se entender a mudança na escola para além de sua superfície, pois inovar na prática docente requer ir além do preparo técnico, da força de vontade e das motivações particulares. Abrange em primeiro lugar uma cultura coletiva para a inovação, que consiste em romper com as velhas práticas, com ideias e valores que se encontram arraigados no contexto histórico-educacional do Ensino Médio (MORAES, 1996). Em segundo, é preciso garantir condições para o trabalho do docente e apoio ao professor inovador para que ele não seja desestimulado enquanto estabelece suas práticas pedagógicas durante a aventura que é inovar (CARBONELL, 2002).

E enfim destacamos que, para que ocorram mudanças no que diz respeito ao Ensino de Ciências é necessário que os professores "acreditem que a mudança é possível” e que estes "possam formar uma representação coerente da inovação pretendida" (CACHAPUZ; PRAIA; JORGE, 2004, p. 378). Desse modo, poderemos propiciar um ensino de Ciências da Natureza melhor para os nossos alunos e em sintonia com as emergentes transformações que ocorrem na sociedade.

\section{Referências}

BRASIL. Ministério da Educação. Secretaria de Educação Básica. Programa Ensino Médio Inovador. Documento Orientador. Brasília: MEC; SEB, 2013a. Versão Preliminar. Disponível em: <www.seduc.mt.gov.br/download_file.php?id=16000>. Acesso em: 25 maio 2013.

Ministério da Educação. Secretaria de Educação Básica. Programa Ensino Médio Inovador. Documento Orientador. Brasília: MEC; SEB, 2013b. Versão Final. Disponível em: <http://portal.mec.gov.br/dmdocuments/documento_orientador.pdf>. Acesso em: 27 jun. 2014.

. Ministério da Educação. Câmara de Educação Básica. Parâmetros Curriculares Nacionais para o Ensino médio. Parte III. Bases Legais. Brasília: MEC; CEB. 2000. Disponível em: <http://portal.mec.gov.br/seb/arquivos/pdf/blegais.pdf>. Acesso em: 20 mar. 2014. 
BRASIL. CNE. Conselho Nacional de Educação. Resolução CNE/CEB 2/2012. Diretrizes Curriculares Nacionais para o Ensino Médio. Diário Oficial da República Federativa da União. Brasília: CNE, 2012. 31 jan. 2012, Seção 1, p. 20.

CACHAPUZ, A. F.; PRAIA, J.; JORGE, M. Da educação em ciência às orientações para o ensino das ciências: um repensar epistemológico. Ciência e Educação, v. 10, n. 3, p. 363-381, 2004.

CACHAPUZ, A. et al. A necessária renovação do ensino de ciências. 3. ed. São Paulo: Cortez, 2011.

CARBONELL, J. A aventura de inovar: a mudança na escola. Artmed: Porto Alegre, 2002.

CARVALHO, A. M. P.; GIL-PÉREZ, D. Formação de professores de ciências. 5. ed. São Paulo: Cortez Editora, 2001. V. 26. (Coleção Questões da Nossa época).

CHARLOT, B. A mobilização no exercício da profissão docente. Revista Contemporânea de Educação, vol. 7, n. 13, p. 9-25, 2012.

CARVAlHO, A. M. P. (Org.). Ensino de ciências por investigação: condições para implementação em sala de aula. São Paulo: Cengage Learning, 2013.

DELIZOICOV, D.; ANGOTTI, J. A. P.; PERNAMBUCO, M. M. C. A. Ensino de ciências: fundamentos e métodos. São Paulo: Cortez, 2002.

FARIAS, I. M. S. Inovação, mudança e cultura docente. Brasília: Líber, 2006.

GALIAZZI, M. C.; GONÇALVES, F. P. A natureza pedagógica da experimentação: uma pesquisa na licenciatura em Química. Química Nova, vol. 27, n. 2, p. 326-331, 2004.

GIL PÉREZ, D. et al. Para uma imagem não deformada do trabalho científico. Ciência e Educação, v. 7, n. 2, p. 125-153, 2001.

HODSON, D. Hacia un enfoque más crítico del trabajo de la laboratório. Enseñanza de las Ciencias, v. 12, n. 3, p. 299-313, 1994.

LENOIR, Y. Didática e Interdisciplinaridade: uma complementaridade necessária e incontornável. In: FAZENDA, Ivani (Org.). Didática e interdisciplinaridade. 13. ed. São Paulo: Papirus, 1998. p. 45-75.

LOPES, A. C.; MACEDO, E. A estabilidade do currículo disciplinar: o caso das ciências. In: LOPES, A. C.; MACEDO, E. (Org.). Disciplinas e integração curricular: história e políticas. Rio de Janeiro, DP\&A, 2002. p. 73-94.

MAINARDES, J. Abordagem do ciclo de políticas: uma contribuição para a análise de políticas educacionais. Educação \& Sociedade, v. 27, n. 94, p. 47-69, 2006.

MALDANER, O. A. A formação inicial e continuada de professores de química: professores/pesquisadores. 3. ed., Ijuí: Ed. Unijuí, 2006. (Coleção Educação em Química). 
MORAES, R.; GALIAZZI, M. do C. Análise textual discursiva. Ijuí: Ed. Unijuí, 2007. MORAES, R.; GALIAZZI, M. C.; RAMOS, M. G. Pesquisa em sala de aula: fundamentos e pressupostos. In: MORAES, R.; LIMA, V. M. R. (Org.). Pesquisa em sala de aula: tendências para a educação em novos tempos. 2. ed. Porto Alegre: EDIPUCRS, 2004. p. 9-24.

MORAES, M. C. O paradigma educacional emergente: implicações na formação do professor e nas práticas pedagógicas. Em Aberto, ano 16, n.70, p. 57-69, 1996.

PRAIA, J.; CACHAPUZ, A.; GIL-PÉREZ, D. Problema, teoria e observação em ciência: para uma reorientação epistemológica da Educação em Ciência. Ciência \& Educação, v. 8, n. 1, p. 127-145, 2002.

RAMOS, M. N. O currículo para o ensino médio em suas diferentes modalidades: concepções, propostas e problemas. Revista Educação e Sociedade, v. 32, n. 116, p. 771-788, 2011.

SANTOS, W. L. P. Contextualização no ensino de ciências por meio de temas CTS em uma perspectiva crítica. Ciência e Ensino, volume especial, 2007.

SCHEID, N. M. J.; FERRARI, N.; DELIZOICOV, D. Concepções sobre a natureza da ciência num curso de Ciências Biológicas: imagens que dificultam a educação científica. Investigações em Ensino de Ciências. Investigações em Ensino de Ciências, v. 12(2), p. 157-181, 2007.

SILVA, R. R.; MACHADO, P. F. L.; TUNES, E. Experimentar sem medo de errar. In: SANTOS, W. L. P. S.; MALDANER, O. A. (Org.). Ensino de química em foco. Ijuí: Ed. Unijuí, 2011. p. 231-261.

ZIBAS, D. M. L.; FERRETTI, C.; TARTUCE, G. L. B. P. A reforma do ensino médio e o protagonismo de alunos e pais. Revista Portuguesa de Educação, 18(1), p. 45-87, 2005. 